\title{
APLICACIONES E IMPLICACIONES DE LAS IDEAS DE M. BAJTÍN EN EL ANÁLISIS DE TEXTOS ESCRITOS POR MUJERES
}

\author{
Mercedes Arriaga Flórez \\ Universidad de Sevilla
}

\begin{abstract}
This article analyses the question of subjectivity and its relation to the notion of identity from a semiotic point of view. The incursion of the idea of alterity (otherness) in the theoretical reflection upon the subject and its signs has encouraged new perspectives within Gender Studies which consider sexual difference as the product of an imposed cultural codification, that is, the result of a forced way of relating ourselves to signs, enabling philosophers and cultural critics to experiment with new ways of presenting and interpreting the symbolic and ontologic status of women. With that aim in mind and trying to dismantle essentialities around the category of femininity, we will study the role played by some ideas by Mikhail Mikhailovich Bakhtin in the analysis of texts written by women, and in the theoretical reflection upon language and other types of sign systems, the patriarchal tradition included, and its relevance to the different aspects of the question of otherness that characterises the feminine.
\end{abstract}

\section{Los AlRededores Semióticos de LAS TeORÍAS DE GÉNero.}

En Tratado de Semiótica General, Umberto Eco indicaba el problema de la relación entre los signos y el individuo, como uno de los últimos desafíos de investigación de la semiótica. Autores como Parret en Francia y Ponzio en Italia, han puesto de manifiesto que el problema de la subjetividad no puede plantearse únicamente en relación con la categoría de la "identidad".

La irrupción de otro concepto, el de la "alteridad", en la reflexión teórica del sujeto y sus signos, ha permitido replantear el estatus simbólico y ontológico de la mujer, desde siempre considerada "lo otro" irreducible con respecto a lo masculino. Y ha impulsado los estudios de género que consideran la diferencia sexual como producto de una codificación cultural impuesta, es decir, resultado de una forma obligada de relacionarnos con los signos. Analizaremos principalmente aquí el papel que algunas ideas de M. Bajtín han jugado en el análisis de textos escritos por mujeres, especialmente en varias tipologías de textos autobiográficos. Algunas de esas ideas han tenido un potencial subversivo decisivo a la hora de desmontar las "esencialidades" en las que se encerraba lo femenino, y también un potencial operativo de trabajo, que permiten visibilizar estructuras literarias, donde se creía que no existían. Aquí se trataran principalmente:

I. La categoría de la alteridad.

II. La teoría del enunciado.

III. La dialogía.

IV. El cuerpo grotesco. 


\section{LA CATEGORÍA DE LA Alteridid}

Cuando M. Bajtín, con sus estudios, cambió el punto de vista de la fenomenología, desde el horizonte del yo al horizonte del otro, no sólo estaba poniendo en discusión la dirección de la filosofía occidental, y la visión del mundo dominante en nuestra cultura, si no que, además, estaba abriendo nuevas posibilidades de análisis para algunos textos escritos por mujeres, que habían permanecido fuera de la literatura.

Dicha categoría se ha demostrado importante en el análisis de los géneros literarios más practicados por las mujeres, es decir, los autobiográficos. El análisis de estos textos se había basado siempre en la categoría de la identidad/identificación, que coincidía precisamente con la de un autor y un protagonista masculinos, y que impedía, entonces, el análisis de textos autobiográficos escritos por mujeres, en los que dicha categoría se encontraba ausente, distorsionada, o intermitente, y en los que, en cambio, la categoría de la alteridad fundaba todo el texto siguiente.

En la afirmación de Bajtín:

El principio interior de la unidad es inútil al relato biográfico, y el yo-para-mi no podría contar nada; sino que es la posición de valor del otro, necesaria para la biografía, es la más cercana a mí, y yo convocado directamente en ella a través de los héroes de mi vida, los demás, y a través de los que la cuentan (Bajtín 1988: 139) ${ }^{1}$.

encuentra amplio eco en muchos textos autobiográficos escritos por mujeres, donde el yo permanece eclipsado, escoge una posición de segundo plano, o cuenta su historia a través de personas interpuestas. Muchas veces se convocan en el texto testigos, amigos y conocidos, a través de la cita de sus palabras directas, o incluso a través de fragmentos de cartas, que son los que darán testimonio del valor del yo, sin que éste tenga que exponerse directamente a través de la primera persona, a través del indicativo, a través del discurso directo.

\section{LA TEORÍA DEL ENUNCIADO}

Si reconocemos, con Bajtín, que cada estilo está ligado a la enunciación y a los géneros de discurso (Bajtín 1988: 248), podemos concluir que el estilo de lo autobiográfico hay que buscarlo, precisamente, en la relación que el autor mantiene con "el otro y con la enunciación" (Bajtín 1988: 288), más bien que en la referencia a la estilística o a la narratología, que definen el estilo en base al contenido del discurso y a la relación que el autor tiene con el mismo. Los elementos que la perspectiva tipológica considera (tanto lingüísticos como narratológicos) tienen un carácter lógico y referencial dentro del texto, determinan los rasgos valorativos, afectivos y modales del texto, pero no pueden detectar la intertextualidad o la dialogía del mismo.

La teoría del enunciado tiene una gran trascendencia para el análisis de algunos textos autobiográficos como son las cartas y diarios, en los que siguiendo a Bajtín, consideraremos el autor, el personaje (el héroe en la terminología bajtiniana) y el interlocutor como elementos constitutivos del texto, puesto que participan en el evento estético, la interacción entre ellos determina la entonación, el estilo y la forma misma del

\footnotetext{
${ }^{1}$ Las citas se refieren a las ediciones italianas. Las traducciónes al español son de la autora.
} 
texto. En los planteamientos pragmáticos, el lector es un receptor ideal, reflejo especular del autor, una especie de doble, y como señala Bajtín "Entre ellos no existe interacción, porque no son voces, sino conceptos abstractos, iguales" (Bajtín 1988: 382). En cambio, si consideramos diarios y cartas como enunciados producidos por una enunciación, se parte de un sujeto que articula el texto, no abstracto ni universal, sino particular y sexuado, que se orienta y toma posición hacia un interlocutor. En el caso de los epistolarios, diferentes críticas han señalado que su análisis, más que responder a los géneros literarios responde a los géneros de discurso teorizados por Bajtín. Desde esta perspectiva, lo epistolar se caracterizaría por ocupar una doble posición de frontera:

a. entre el yo que escribe y su destinatario y/o interlocutor,

b. entre la objetivación de la escritura y la referencia a la vida.

Hay otra cuestión fundamental, y es que en la discusión de si estos textos pertenecen o no al ámbito de la literatura, Bajtín nos socorre para aclarar la cuestión: aunque los diarios y las cartas no respondan a las categorías establecidas, no quiere decir que puedan escapar al terreno de lo literario, es más, como sostiene Deleuze: "las cartas postulan directa, inocentemente, la potencia diabólica de la máquina literaria" (Deleuze 1978: 46). Aunque las cartas nazcan en un "contexto de negligencia" (Ferraro 2000: 225), término que acuña Valerio Ferraro para indicar su improvisación y su falta de intención literaria, subrayando que son una forma de escritura que quedan fuera de la littera como "oficio" y "disciplina", eso no significa que puedan eludir lo literario como comportamiento escrito. De hecho, Bajtín señala que lo cotidiano no queda fuera de la representación, y que, por lo tanto, está sometido a una interpretación cultural y a una codificación literaria:

"La pura cotidianidad es una fícción, una invención de intelectuales. La vida cotidiana humana tiene siempre una forma y esta forma es siempre ritual (al menos estéticamente). Sobre esta ritualidad puede apoyarse la imagen artística" (Bajtín 1988: 373)

Que el diario, las cartas o los cuadernos de apuntes tengan una dimensión pública o no, es irrelevante para el carácter comunicativo y para el valor literario, porque como dice Bajtín "dar cualquier motivación del propio gesto o tomar conciencia de sí mismos (de hecho la autoconciencia es siempre verbal, se reduce siempre a la elección de un determinado complejo verbal), significa sujetarse a una forma social cualquiera, a una valoración social, significa, por decirlo así, socializarse a sí mismos y el propio acto" (Bajtín 1979: 156-157).

\section{LA DiALOGíA.}

La dialogía bajtiniana va más allá de la intertextualidad propuesta por la semiótica, en la que el autor solamente es un anillo de la cadena de comunicación y su texto un proceso de intersecciones en las que "leer" otros textos. La dialogía puede usarse para descubrir la "polémica interna" que los textos autobiográficos escritos por mujeres mantienen con la tradición patriarcal (Díaz Diocaretz, 1993: 77-124). Esta categoría ha sido aplicada por teóricas como Iris Zavala (1997) y Miriam Díaz Diocaretz (1993) a textos como los de Sor Juana Inés de la Cruz, para concluir que la pretendida sencillez y espontaneidad del texto articula en realidad juegos lingüísticos y estrategias retóricas que desafían las jerarquías y desmontan las esencialidades. 


\section{El CUERPO GROTESCO}

El realismo grotesco es una forma utilizada por las escritoras, y por las artistas, para mostrar la disconformidad con los cánones estéticos de belleza imperantes (Frida Kahlo, Merini, etc.). La noción del cuerpo grotesco y del cuerpo carnavalizado con todo su potencial subversivo, se convierte en una categoría imprescindible para analizar las obras de escritoras como Alda Merini o Janet Frame.

La noción de cuerpo femenino que Alda Merini perfila se representa a través de lo grotesco, tanto en su aspecto de metáfora corporal, como en su aspecto de revalorización de lo marginal. En este sentido, da continuidad a los mitos de la Gran Madre (Neumann 1981), y de la Diosa Madre (AA.VV. 1989). Tanto el "grotesco" como el de la Gran Madre son cuerpos abiertos, expuestos, visitables, cuerpos "ánforas", que contienen el mundo, cuerpos desproporcionados en los que lo interno se hace externo y viceversa, cuerpos-pasadizos donde se funden dimensiones diferentes como lo humano y lo animal, lo animado y lo inerte.

El cuerpo de mujer representa en la poesía de Alda Merini el lugar de lo oculto, de lo húmedo, de lo escondido y misterioso, de lo material y de lo oscuro, que se concretan en las figuras simbólicas de la mujer "monstruosa", "anormal": histérica, medusa, hidra, vieja, beduina, maga, salvaje. El cuerpo de la mujer es "bicorporal", contiene y crea otro cuerpo. Es un cuerpo no delimitado, en proceso de construcción y de creación, a través del cual se une con otros cuerpos y con el mundo. Este cuerpo "grotesco" recupera de forma existencial para la mujer un modo de relacionarse consigo misma, con los demás y con el mundo que la ideología dominante impide.

Lo "grotesco femenino" (Russo 1994), posee al mismo tiempo un carácter subversivo y un proyecto utópico, en los que se afirman nuevas metáforas y nuevas perspectivas desde las que afrontar la realidad, y en este sentido se relaciona directamente con lo subversivo carnavalesco.

\section{El Tercero Ausente}

Si el enunciado, y por extensión el texto, se dirige siempre a alguien, es decir, presupone siempre dos personas por lo menos, en el caso de los textos autobiográficos escritos por mujeres, sobre todo antes del siglo XX, este destinatario "natural" del texto muchas veces es un hombre que ocupa una posición de poder con respecto a la escritora. Asistimos así a una doble destinación del texto que se coloca en una doble posición, se dirige al destinatario que puede hacer que el mismo texto sobreviva y se inserte en la cadena de transmisión de la cultura, pero en su contenido prevé un destinatario/a diferente, que podríamos identificar con el Tercero ausente de Bajtín:

El autor prevé de forma más o menos consciente un superdestinatario superior (el tercero), cuya comprensión y respuesta absolutamente imparcial presupone una lejanía metafísica, o un alejado tiempo histórico. (El destinatario - fuga) (Bajtín 1988: 306)

Ahora bien, ese Tercero ausente en nuestros textos se identifica sobre todo con las lectoras del futuro. De ellas vendrá la comprensión de las zonas oscuras del texto, la interpretación de lo que el texto calla, y sobre todo, la respuesta a los interrogantes que el texto plantea. "Lo silenciado", que se oculta a través de estrategias retóricas concretas, y se 
esconde sobre todo en el tono más que en los elementos lingüísticos y filológicos, está destinado a la comprensión-reconocimiento de los/as que han de venir, que se convierten en el centro axiológico del texto.

\section{REFERENCIAS BIBLIOGRÁFICAS}

AA. VV., Le grandi madri, Milano, Feltrinelli, 1989.

BAJTÍN, M., Estetica e romanzo, Torino, Einaudi, 1975.

BAJTÍN, M., L'autore e l'eroe, Torino, Einaudi, 1979.

BAJTÍN, M. , Teoria letteraria e scienze umane, Torino, Einaudi, 1988.

DELEUZE, G./GUATTARI, F., Kafka: por una literatura menor, México, Era, 1978.

DÍAZ DIOCARETZ, M., Breve historia feminista en la literatura española (en lengua castellana), vol. I, Barcelona, Anthropos, 1993.

ECO, U., Trattato di semiótica generale. Milano, Bompiani, 1993.

FERRARO, V., "Considerazioni sullo spazio epistolare del Novecento: il contesto della negligenza," en Locatelli, C. (ed.), Co(n)texts: Implicazion testuali, Trento, Università di Trento, 2000.

NEUMANN, E., La grande madre, Roma, Astrolabio, 1981.

PONZIO, A., La relazione interpersonale. Bari, Adriatica, 1967.

PONZIO, A., Soggetto e alterità, Bari, Adriatica, 1987.

RUSSO, M., The Female Grotesque. Risk, Excess and Modernity, New York, London, Routledge, 1989.

ZAVALA, Iris (1997): Breve historia feminista en la literatura española (en lengua castellana), Vol. IV, Barcelona, Anthropos. 
